\title{
GRAPH-DEMONSTRATION OF THE SOLUTIONS OF ENGINEERING TASKS
}

\author{
Fruzsina HORVÁTH ${ }^{1}$, László POKORÁDI ${ }^{2}$ \\ ${ }^{1}$ Óbudai University, Student Workshop of Technical Safety Sciences, Budapest, Hungary, \\ hrvt.fruzsina@gmail.com \\ ${ }^{2}$ Óbuda University, Institute of Mechatronics and Vehicle Engineering, Budapest, Hungary, \\ pokoradi.laszlo@bgk.uni-obuda.hu
}

\begin{abstract}
During technical education it is a very difficult yet essential task to develop the good logical engineering thinking of students or pupils. One main part of this thinking is the determination of the optimal set of required input parameters for the calculation task mentioned above. The LogTreeMM (Logical Tree of Mathematical Modelling) method can help to solve this task. The aim of this paper is to show modification of the LogTreeMM method to determine the required parameters of a mathematical model by a simple case study.
\end{abstract}

Keywords: mathematical model, logical graph, STEM education.

\section{Introduction}

In today's technologically advanced world, technical studies play a particularly important role. To understand this world and to prosper, we must have comprehensive and sufficiently profound engineering knowledge. During higher education, students meet complex problems and tasks which require the identification of the deeper connections inherent in them. These goals are summed up by the so-called STEM (Science, Technology, Engineering and Mathematics) education. STEM is a new educational policy approach [1]. In this paper the modification of LogTreeMM (Logical Tree of Mathematical Modelling) method is presented, which can be used effectively in the case of teaching and learning in the engineering disciplines. The original procedure is described in the literature [2]. The proposed method is a well-known graph-based analysis. The method systematically shows the solution of an engineering problem step by step, while showing the connections between the steps as well. It presents expressively the logical and physical structure of the solution of an engineering task, so the solving opportunities of more complex problems can be visually clear and interpretable for the students.

\section{Case study}

The method is presented and illustrated by the following simple physical case which makes it easier to understand the proposed method. The case study is the adaptation of the task, which is presented in the article [3] written by Bera and Pokorádi, derived from the course book of Gelencsér [4]. Basically the logic of solution has not been changed, only its representation is different. It is important to mention that the method can not only be applied within the subject of mechanics, but can be used for any task.

A box with mass $m$ is started from the top of the slope with starting velocity $v_{0}$ (Figure 1.). The question is as follows: What is the kinetic energy of this box at the bottom of the slope?

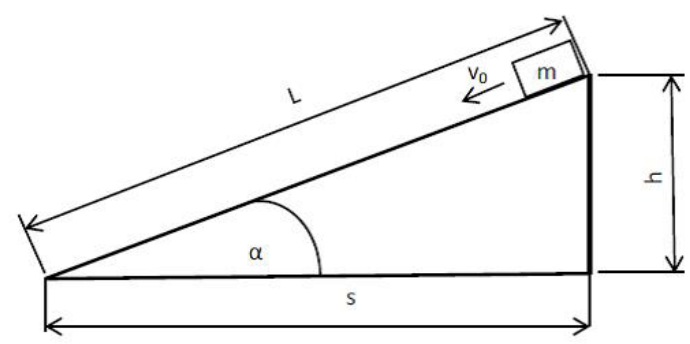

Figure 1. Illustration of the Example 
As a first step in answering the above question, we should think about possible solutions of the given engineering task.

There are two different relationships for determining the kinetic energy:

$$
\begin{aligned}
& E_{m}=\frac{m v_{0}^{2}}{2}+m g L \cdot \sin \alpha \\
& E_{m}=\frac{m v_{0}^{2}}{2}+m g h
\end{aligned}
$$

Basically, the task can be solved by using one of them, so between them an OR logical connection is presented. As we can see, two equations are presented, so we should choose the calculation mode and required data.

If we use equation (2), we should move on the "blue solution path" (see Figure 2.), so the required input parameters will be known, these are as follows: mass $m$ AND initial velocity $v_{0}$ AND acceleration of gravity $g$ AND height of slope $h$. Because all of these parameters are needed, between them the AND logical gate should be introduced.

The other solution is solving equation (1). These pathways have been marked in brown, green, red and orange.

To solve equation (1) we should know the following parameters: mass $m$ AND initial velocity $v_{0}$

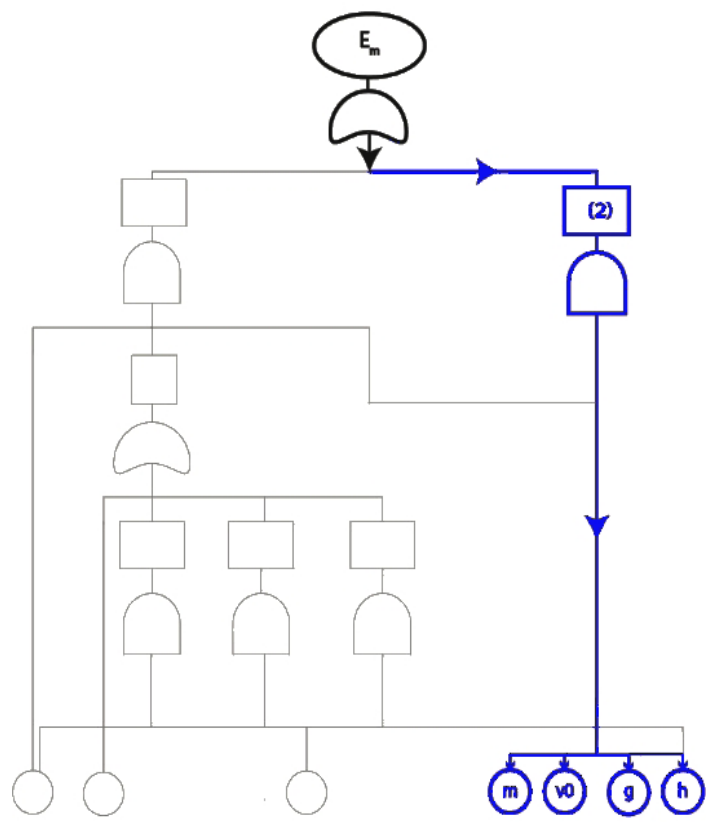

Figure 2. The "blue solution path"
AND acceleration of gravity $g$ AND length of slope $L$ AND angle of slope $\alpha$.

The most interesting is the angle of slope $a$. This parameter can be determined directly (see red path), and by using lots of trigonometric relationships. These relationships are depicted by equations (3) - (6).

Using relationship

$\alpha=\arcsin \frac{h}{L^{\prime}}$

we should know height of slope $h$ AND length of slope $L$.

If we use equation

$\alpha=\arccos \frac{S}{L^{\prime}}$

the horizontal spread of the slope $S$ parameter should be known too.

In case of using equation

$\alpha=\arctan \frac{h}{S}$

the required parameters are height of slope $h$ AND horizontal spread of the slope $S$.

The application of equation

$\alpha=\operatorname{arccot} \frac{S}{h}$

requires height of slope $h$ AND horizontal spread of the slope $S$ parameters, as in equation (5).

The red-colored solution method in Figure 3. uses only equation (1), for which mass m, acceleration due to gravity $g$, length of slope $L$, initial velocity $v_{0}$, and angle of slope $\alpha$ parameters must be known. In this solution method, $\alpha$ is treated as a basic variable as well, so we get it directly after the OR gate, and the usage of any other equation and parameters are not needed.

However, in the case of the green path of Figure 3., it is no longer a simple task, because equation (3) must be used in addition to equation (1). The required parameters for this are mass $m$, acceleration of gravity $g$, length of slope $L$, initial velocity $v_{0}$ and height of slope $h$.

In the case of orange version, we should use equations (4) and (1), for which mass $m$, acceleration of gravity $g$, length of slope $L$, initial velocity $v_{0}$ and horizontal spread of the slope $S$ variables are needed.

If equations (5) and (1) are to be used (brown path), the necessary parameters are mass $m$, acceleration of gravity $g$, length of slope $L$, initial velocity $v_{0}$, horizontal spread of the slope $\mathrm{s}$ and 


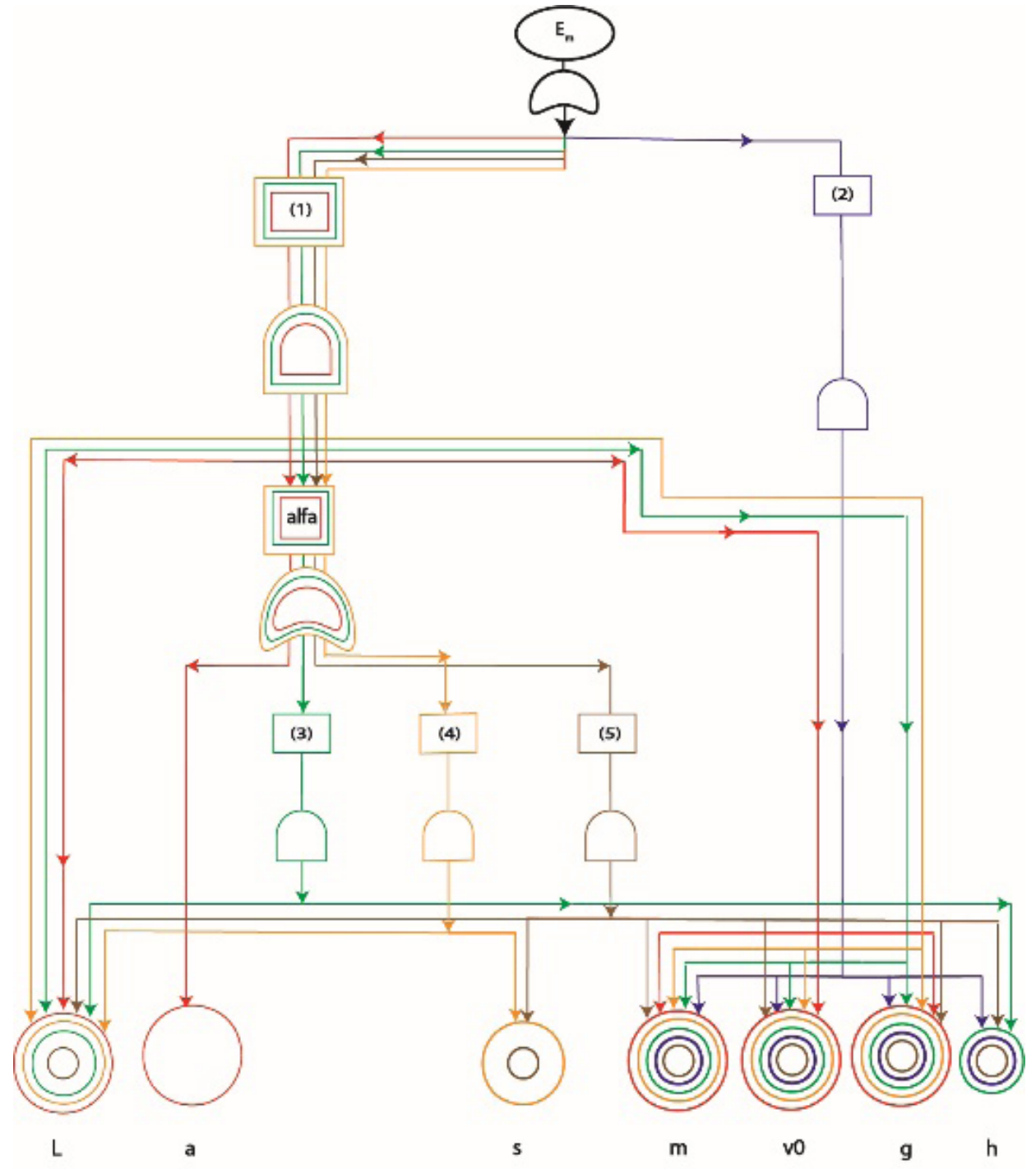

Figure 3. The logical network of the sample task

height of slope $h$. With this diagram, however, the solution method using equations (6) and (1) can be illustrated as well; since horizontal spread of the slope $S$ and height of slope $h$ parameters are also needed to solve the arcus cotangents function.

After each version of the solution are taken into consideration, we must look at the summary figure showing all the paths and think about what conclusions can be drawn from it. In Figure 3. the most striking and most spectacular fact is that 5 different modes can be used to solve the problem of the task, if equation (6) is not considered as a separate solution.
It can also be seen clearly in Figure 3 . that the shortest and easiest path belongs to the blue version, where knowing 4 basic variables are enough. By contrast, for the brown-colored solution, 6 variables must be known and used to successfully complete the task. These variables are initial velocity $v_{0}$, acceleration of gravity $g$, mass $m$, length of slope $L$, angle of slope $\alpha$, height of slope $h$, from which we can easily deduce that this path requires the most parameters, so this is the longest of all.

In addition, the figure shows that initial velocity $v_{0}$, acceleration of gravity $g$, and mass $m$ parameters are necessary for all solutions with all 
five times, since these variables are used by all solution paths. Since these are basic variables, we need to know them from the description of the task, and $\mathrm{g}$ as a physical constant, which is the internationally accepted basic value of acceleration.

\section{Summary}

In this paper a modified Logical Tree of Mathematical Modelling method has been shown using an easy case-study.

We think that the guidelines set out in the STEM approach can contribute to a more successful education. It is important to focus not only on the superficial learning of the curriculum, but also to try to apply this knowledge and to deepen it in the learning process.

\section{Acknowledgments}

This work has been supported by supported by the ÚNKP-17-1 New National Excellence Program of the Ministry of Human Capacities, Hungary, which is gratefully acknowledged. This work has been done at Óbuda University, Student Workshop of Technical Safety Sciences $-\mu \beta \sigma$.

\section{References}

[1] Horváth F.: Mérnöki számítások megoldásainak gráf-szemléltetése. TDK-dissertation, Óbuda University, Donát Bánki Faculty of Mechanical and Safety Engineering, Budapest, 2017.

[2] Pokorádi L.: Logical Tree of Mathematical Modeling. Theory and Applications of Mathematics \& Computer Science 5/1. (2015) 20-28.

[3] Bera B., Pokorádi L.: A LogTreeMM szemléltetése. In: A XX. Fiatal müszakiak tudományos ülésszak előadásai. Proceedings of the 20th international scientific conference of youngth engineers, Kolozsvár/Cluj, Kolozsvár, Románia, Müszaki Tudományos Közlemények 3. (2015), 75-78. https://eda.eme.ro/handle/10598/28669

[4] Gelencsér E.: Mozgástan zárthelyi feladatok BSc, Szent István Egyetemi Kiadó, Gödöllő, 2014. 124. 